\title{
The Research about Russian Higher Education Joining the Bologna Process
}

\author{
Yuliia Khoruzha \\ School of Vocational Education, Tianjin University of Technology and Education, Tianjin, China \\ Email: 1990322801@qq.com
}

How to cite this paper: Khoruzha, Y. (2018) The Research about Russian Higher Education Joining the Bologna Process. Open Access Library Journal, 5: e4355. https://doi.org/10.4236/oalib.1104355

Received: January 22, 2018

Accepted: February 20, 2018

Published: February 23, 2018

Copyright ( $\odot 2018$ by author and Open Access Library Inc.

This work is licensed under the Creative Commons Attribution International License (CC BY 4.0).

http://creativecommons.org/licenses/by/4.0/

\begin{abstract}
The aim of this paper is to study a series of reforms in Russia's higher education after joining the Bologna Process, to analyze difficulties and problems that Russia's higher education has encountered during the process of reform, and to understand the extent of Bologna's progress in Russia and process of the implementation.
\end{abstract}

\section{Subject Areas}

Education

\section{Keywords}

Bologna Process, Russian Higher Education, Reform

\section{1. 引言}

苏联解体后, 俄罗斯的高等教育受到了重创, 教育水准下降的很严重。 然而, 近些年, 俄罗斯大力发展高等教育, 现在整个俄罗斯已经有 1000 多家 高等院校, 涉及了各个专业。俄罗斯国立大学是俄罗斯一流的高等院校, 俄 罗斯国立大学的文凭已经得到了很多国家的认可。除此以外, 俄罗斯还是世 界上最早的和中国签订学历互认的国家之一。俄罗斯的高等教育近些年发展 的非常不错, 在航天、物理、软件、财务、设计等方面都有着明显的优势。 俄罗斯有着来自全世界各个国家的留学生在俄罗斯学习。俄罗斯也积极的加 入欧盟高等教育一体化进程中，在博洛尼亚进程中，提高了俄罗斯的师资力 量、人才的竞争力，但是改革的同时，也面临了一些困难和阻力。

\section{2. 博洛尼亚进程的概述}

首先，跨文化的高等教育交流在古代欧洲就已经有了先例，早在古希腊 
和古罗马时期, 欧洲的各个国家就已经进行了跨文化的交流, 当时的表现形 式为游学, 学生和教师在各个城邦之间交流和学习, 促进了各个城邦之间的 文化交流, 也让古希腊和古罗马的历史文化甚至影响到今天。其次, 第二次 世界大战以后, 欧洲已经逐渐没落, 欧洲的高等教育已经远不如美国, 各个 国家的优秀学生都以美国的高校为申请目标。通过跨文化的交流一方面可以 帮助各个高等院校筹集经费, 另一方面通过跨文化的高等教育交流, 可以吸 收全球范围内的优秀学生, 提高各个国家的高等教育竞争力。最后, 博洛尼 亚进程可以促进欧盟一体化。自 1993 年欧盟成立以来, 欧盟的各个成员国之 间的政治经济之间的交流越来越广泛, 对于国际化人才的需求也越来越多, 在经济政治各个领域都需要具有国际视野的符合各个国家需要的人才。同时, 欧盟这些年一直在构建 “欧洲公民”, 通过文化的交流可以增加青年人对 “欧 洲公民” 的认同感，同时促进文化一体化。

\section{1. 博洛尼亚进程的建立过程博洛尼亚进程的阶段}

在博洛尼亚进程全面启动之前, 欧盟的一些国家已经对欧洲教育的一体 化做出了一定的贡献。1998 年 5 月, 德国、意大利、英国和法国的教育部长 就在索邦大学探讨了四国之间的高等教育、学分体系等问题, 并且认为大学 可以促进各个国家的交流和合作。《索邦宣言》标志着博洛尼亚进程的全面 启动 $[1]$ 。

博洛尼亚进程全面启动于 1999 年, 经过 10 年对高等教育区的研究和建 设, 在博洛尼亚, 欧盟的 29 个国家的教育部长提出到 2010 年建设完成欧洲 高等教育区。这就是著名的《博洛尼亚宣言》[2], 在这个会议上, 确定了欧 洲高等教育区的具体内容, 并且提出了最高纲领。

在后续的几年中, 博洛尼亚进程不断的完善。2001 年, 在布拉格, 欧盟 的 29 国教育部长提出了终身教育、学生参与、增强欧洲高校吸引力的纲领。 2005 年, 卑尔根会议, 提出应当保证各个成员国高等教育的质量。2007 年, 在伦敦会议上, 与会的各国提出应当开展信息搜集工作, 保证教育质量, 并 且要对各个国家的学位体系进行完善。

\section{2. 博洛尼亚进程的内容}

第一, 博洛尼亚进程建立了一个统一学位体系和学分制度, 参与博洛尼 亚进程的国家较多, 所以统一的学分制度可以保证各个国家进行统一和互认, 各个国家之间的体系都可以进行比较。

第二, 这个教育体系非常完整, 包括了本科、硕士以及博士, 这样以来, 可以确保人才的供应以及保证高等人才可以和美国相比较。

第三, 建立欧洲学分转换体系(ECTS), 博洛尼亚进程前的学分仅仅包括 的是学时, 即在校上课时间。博洛尼亚进程后的学分还包括了 13 个小时的社 会实践、教师辅导和考试[3]。

第四, 促进老师和学生在各个高校的流动。老师和学生可以在各个国家 的各个高校之内相互的交流, 教师的交流项目以苏格拉底命名, 截止 2016 年, 欧盟已经有 3212 所学校加入了这个项目[4]。 
第五, 保证了欧洲高等教育的教育质量。由于学分统一, 各个高校的学 生可以相互交流和流动, 这样一些优秀的学生就希望能够去更加优秀的学校, 高校只能通过不断提高教育质量, 保证优秀学生能够留在本校, 同时吸引其 他高等院校的优秀学生。

第六, 促进欧洲范围内的高等教育合作。。由于学位体系和学分制度的 统一, 各个国家之间进行教育合作。一个国家的大学可以选择另一个国家的 大学共同开展课程, 学生在这两个学校修学以后, 可以获得两个大学的文凭, 同时也获得了国际视野。

\section{3. 俄罗斯加入博洛尼亚的背景}

第一, 提升国家竞争力的需求。苏联解体之后, 俄罗斯作为苏联的前身, 与资本主义国家的联系比较松散, 俄罗斯作为一个新资本主义国家, 迫切的 需要与西方的资本主义国家加强合作, 所以, 俄罗斯加入欧盟这个组织, 希 望能够通过与欧盟的关系加强俄罗斯的竞争力[5]。俄罗斯需要与欧盟保持紧 密的关系, 所以俄罗斯选择通过博洛尼亚宣言加强与欧盟之间的教育联系, 通过人才的交流促使俄罗斯公民有着“欧洲公民”的意识, 加强与欧盟之间的 利益基础。

第二, 提高俄罗斯高等教育水平。俄罗斯传统的高等教育已经不适用于 目前国际化的社会, 之前传统的只注重理论缺乏实践的教育已经满足不了俄 罗斯对人才的需求, 通过加入博洛尼亚进程可以提高俄罗斯的高等教育水平。

第三, 增强俄罗斯教育吸引力。美国、欧洲的高等教育比较发达, 很多 优秀的学生都选择去这些国家进行留学, 只有很少的学生来到俄罗斯留学, 俄罗斯加入博洛尼亚进程能够吸引更多来自海外的留学生, 加强文化的交流 和合作, 增强俄罗斯的教育吸引力, 留住更多的学生[6]。

俄罗斯加入博洛尼亚进程是俄罗斯政府权衡政治、经济、文化多方面的 选择, 俄罗斯在逐渐转型, 俄罗斯已经逐步由石油、武器等硬实力转为一些 软实力, 用软实力来吸引更多的人才建设俄罗斯。

\section{4. 俄罗斯加入博洛尼亚的高等教育状况}

\section{1. 俄罗斯高等教育状况}

苏联解体以后, 教育也受到了巨大的打击, 在经历了一段时间的恢复之 后, 俄罗斯的高等教育才慢慢的走上正轨。

1) 高等教育结构

前苏联的高等教育结构分为本科和研究生两种, 这种分法比较粗略, 不 利于现在日益精化的经济社会结构, 同时, 也很不利于与其他国家进行交流。 后来, 经过数年的研究和变革, 俄罗斯的高等教育结构分为不完全高等教育、 基础高等教育、完全高等教育和研究生后教育这四种[7]。不完全高等教育是 初级, 相当于培训职业资格, 与中国的专科相类似。基础高等教育分为两年 和四年, 两年的为修完不完全高等教育之后再进行的, 相当于中国的专升本。 四年制招生对象是中学生。相当于中国的本科。完全高等教育, 学制两年, 
相当于中国的硕士。研究生后教育, 相当于中国的博士生。

2) 高等院校类型

分为短期学院、综合大学、学院和研究生院 [8]。俄罗斯的高等院校非常 的多, 层次也很丰富, 可以为俄罗斯的经济发展培养不同层次的学生人才。

\begin{tabular}{cc}
\hline 俄罗斯高等院校类型 & 数量 \\
\hline 短期学院 & 16 \\
综合大学 & 698 \\
学院 & 805 \\
研究生院 & 358 \\
\hline
\end{tabular}

数据来源: High education in Russia.

3) 课程设置

俄罗斯的课程设置分为基础课、专业课、专门化课程。

基础课主要就是为后续的专业课打下基础, 同时通过体育等课程让学生 能够展现自己的个性[9]。比如 1995 年, 莫斯科大学财务系学生的基础课程包 括: 体育、计算机、外国语、微观经济学、宏观经济学、政治、经济数学等。 专业课就是学习本专业的基础课程, 同时能够了解行业内的最新的发展 方向, 同时能够学会用理论指导实践, 用所学的知识技能解决工作上面的问 题。

专门化课程, 学生在学习基础课和专业课的基础之上要选择一门专门化 课程, 通过专门化课程深入了解学习的主要内容。以研究和分析为主。

俄罗斯由于体制等原因, 和欧盟的其他的国家一直不能进行教育和文化 方面的交流, 所以, 2003 年, 俄罗斯通过加入博洛尼亚宣言, 能够有机会与 各个国家进行交流。

\section{2. 加入博洛尼亚进程后的俄罗斯高等教育的改革}

2003 年俄罗斯通过柏林会议加入博洛尼亚进程, 加入博洛尼亚进程之后 的俄罗斯高等教育的变革主要是以下几个方面:

1) 采取学分制

在加入博洛尼亚进程之前, 俄罗斯的高等教育采用的是学时制, 而加入 博洛尼亚进程之后, 俄罗斯采用的是学分制, 通过学分制可以方便各个国家 之间的高等教育交流, 同时也方便两个学校对学生的学习情况进行考核[10]。 除此以外, 加入博洛尼亚进程之后, 还对学分制进行了考核, 分为 A、B、C、 D、E、F、FX, 学生在学习的同时也会关注自己的学习成绩, 更好的提升自 己, 提高了俄罗斯高等教育的质量。

2) 教育内容的变革

首先, 加入博洛尼亚进程之前, 俄罗斯的学生想要进行高等教育学习, 需要参加的是各个高校的自主命题考试。加入博洛尼亚进程之后, 俄罗斯推 行了全国范围内的统一考试, 这种考试形式类似于中国的高考制度, 对所有 的中学毕业生都是统一的标准和统一的要求, 可以客观的评价中学生的学习 
成绩和学习能力, 方便各个高校选拔人才, 给予每个学生公平的求学机会。

其次，国家记名义务投资，国家记名义务投资相当于中国的奖学金制度， 在统一国家考试中成绩较高的学生将会获得国家记名义务投资, 通过国家记 名义务投资可以确保一些贫困且优秀的中学生能够得到高等教育的机会, 同 时也提高了俄罗斯高等教育的普及率[11]。

3) 学生和教师的流动

首先, 俄罗斯有一定的拨款机制, 不光是对国内学生到国外留学, 还给 予国外学生来到俄罗斯留学, 促进俄罗斯学生在世界范围内的流动。其次, 加入一些国际化的课程, 譬如国际贸易、外国语等课程, 截止到 2016 年, 俄 罗斯的教育部已经加入了 83 个国际课程[12]。最后, 采用的是博洛尼亚进程 中的标准的学分制度, 方便与各个国家进行文化的交流和合作。

\section{5. 反思与评价}

\section{1. 博洛尼亚进程带给俄罗斯的挑战}

1) 立法支持不足

俄罗斯很多地区的政府并不在意当地的教育水平和教育质量, 对教育重 视程度不够，所以很多地区的高校没有办法获得政府资金以及政策的支持。 除此以外, 很多地区即使对教育重视, 但是政府的工作效率比较低下, 政府 的立法以及适应不了教育改革的速度。

2) 学分系统发展较慢

根据监管俄罗斯加入高等教育进程的报告中显示, 即使加入博洛尼亚进 程, 俄罗斯的学分系统仍然发展的比较缓慢, 很多学校仍然不愿意选择学分 系统, 只有 54\%的俄罗斯高等院校选择了学分系统。主要有以下几个原因, 第一很多学校认为不能量化学生的工作量, 所以就不能给予评分。第二, 很 多学校对教育部的建议不能十分的理解, 对于此仍然存有一定的疑虑, 所以 不愿意采取学分系统[13]。

3) 不能提出个性化学习计划

俄罗斯教育部鼓励学校根据学生的具体情况提出个性化的学习计划, 但 是根据调查显示, 很多高等院校对个性化的学习计划了解的不是很深入, 更 谈不上为学生提供个性化的学习计划或者根据学生的不同情况提供不同的课 程。现在的高等院校仅仅是根据总体的课程, 或者固定的课程。

4) 很难促进学术交流

根据 2016 年 Bulletin of the Russian Education 报道显示, 只有约 34\%的高 等院校的学分系统能够得到欧盟其他成员国的承认。除此以外, 只有 $42 \%$ 的 高等院校愿意承认欧盟成员国其他国家的高等院校成绩单。很多学生在获得 其他国家的学分, 但是回到本国学校必须通过母语考试, 这样他们的学分才 能得到承认。高等院校反馈, 因为学术交流缺乏一些相关的文件, 所以, 很 难得到充分的实施。除此以外, 俄罗斯学生获得的留学机会也比较少。

\section{2. 博洛尼亚进程带给俄罗斯的好处}

首先, 引进的更短的学分系统, 可以缩短俄罗斯培养人才的时间, 解决 
了俄罗斯现代社会就业力的问题。其次, 通过学分系统, 能够让老师和学生 更有创造力和活力, 可以有一定的选择机会, 学生可以选择不同的老师, 这 样提高了学生的兴趣, 也方便学生根据个人的兴趣发展自身。再次, 俄罗斯 对学术交流进行了拨款, 如果学生和老师能够获得学术交流的机会, 那么对 他们来说就是一个比较好的激励作用, 鼓励他们在学术方面进行深造。

\section{6. 总结}

总体来说, 博洛尼亚进程对于俄罗斯的高等教育是一项非常重要的改革, 一方面提高了自己在欧洲影响力, 加入到了欧洲一体化的进程之中, 同时也 获得了一些教育方面的启示。另一方面, 加入博洛尼亚进程也给俄罗斯带来 了一定的挑战。俄罗斯加入博洛尼亚的时间还长, 还有很大的空间进行发展。

\section{References}

[1] 谌晓芹. 欧洲高等教育一体化改革: 博洛尼亚进程的结构与过程分析 [J]. 高等教 育研究, 2012, 33(6): 92-100.

[2] 朱佳妮. 搭乘欧洲高等教育一体化快车?-—“博洛尼亚进程”对德国高等教育的 影响[J]. 清华大学教育研究, 2014, 35(6): 66-74.

[3] 乔莉莉. 俄罗斯实施博洛尼亚进程的进展、争议与发展趋向 [J]. 外国教育研究, 2017, 44(4): 66-76.

[4] 王书武. 博洛尼亚进程对俄罗斯参与全球化的影响 [J]. 西伯利亚研究, 2009, 36(1): 36-38.

[5] 邢文英, 李兰冬, 封文娜. 博洛尼亚进程中俄罗斯高等教育改革对我国的启示 [J]. 中国成人教育, 2013(12): 100-102.

[6] 孟繁红. 俄罗斯高校对博洛尼亚进程的参与[J]. 教育评论, 2011(4): 160-162.

[7] Telegina, G. and Schwengel, H. (2012) The Bologna Process: Perspectives and Implications for the Russian University. European Journal of Education, 47, 37-49. https://doi.org/10.1111/j.1465-3435.2011.01506.x

[8] Esyutina, M., Fearon, C. and Leatherbarrow, N. (2013) The Bologna Process in Higher Education: An Exploratory Case Study in a Russian Context. Quality Assurance in Education, 21, 145-161. https://doi.org/10.1108/09684881311310683

[9] Buniatian, A.A., Vyzhigina, M.A. and Sizova, Z.M. (2008) Conceptual and Methodological Rationales for the Use of Innovational and Traditional Educational Technologies for the Postgraduate Training of Physicians in the Area of Anesthesiology and Reanimatology. Anesteziologiya i Reanimatologiya, 9, 12.

[10] Vyzhigina, M.A., Buniatian, A.A., Sizova, Z.M., Protopopova, T.A., Zaugol'nikova, T.V. and Zhukova, S.G. (2007) Role of a Credit System in the Development of Continuous Postgraduate Training of Physicians within the Framework of the Innovation Educational Space Formation Program of the I. M. Sechenov Moscow Medical Academy. Anesteziologiya i Reanimatologiya, 14, 42-43.

[11] Kozachek, A. (2015) The Bologna Professional Training Degrees in Europe and Russia: Analysis and Systematization. Procedia - Social and Behavioral Sciences, 20, 214.

[12] Aydarova, O. (2014) Universal Principles Transform National Priorities: Bologna Process and Russian Teacher Education. Teaching and Teacher Education, 37, 64-75. https://doi.org/10.1016/j.tate.2013.10.001 
[13] Davydov, I.S. (2006) The Bologna Process and the New Reforms of Russian Education. Russian Education \& Society, 48, 17-32.

https://doi.org/10.2753/RES1060-9393480702 